\title{
O PROCESSO DE ENVELHECIMENTO DE CASAIS FISICAMENTE ATIVOS
}

Mariana Pes Turchiello; Universidade Federal de Santa Maria; marianapes@hotmail.com

Angelita Alice Jaeger; Universidade Federal de Santa Maria; angelita@ufsm.br

\section{RESUMO}

Introdução: O processo de envelhecimento não é um processo homogêneo tampouco tem um padrão, diferenciando-se de acordo com a cultura e com o momento histórico de cada sociedade. Em razão do aumento da longevidade há uma maior busca por um estilo de vida ativo. As transformações corporais são influenciadas por diferentes marcadores, entre os quais o gênero se destaca. Apesar de existirem vários estudos que mostrem que o estilo de vida ativo é benéfico nota-se que há uma lacuna quanto ao estudo do estilo de vida ativa na vida de casais em processo de envelhecimento. Objetivo: analisar as diferenças de percepção das relações de gênero no envelhecimento de casais fisicamente ativos. Métodos: Utilizou-se uma abordagem qualitativa de pesquisa. A partir de uma amostra intencional, participaram da investigação 8 casais heterossexuais, com idades variando de 53 e 79 anos, autodenominados brancos, de classes alta e média alta. Realizou-se entrevistas semiestruturadas individualmente, gravadas em um dispositivo digital e após transcritas literalmente. O material empírico foi organizado e analisado com o auxílio do software Nvivo 12. Resultados: Formaram-se 3 categorias que apontaram que as escolhas das práticas corporais são múltiplas, predominantemente individuais para as mulheres e, coletivas e individuais para os homens, os benefícios eram o fator motivador, incluíram alívio da dor, melhor alinhamento postural e maior disposição. Alguns/as entrevistados/as mencionaram pequenos incômodos com as transformações corporais. Conclusão: Conclui-se que a pesquisa contou com um grupo seleto, adepto aos cuidados corporais, os quais vivenciam o processo de envelhecimento de forma leve e saudável.

Palavras-chave: Envelhecimento Saudável; Estudos de Gênero; Atividade Física 